\section{SPARX computerised CBT is as effective as usual care for mild- to-moderate depression in help seeking adolescents}

\begin{abstract}
QUESTION
Question: Is a computerised cognitive behavioural therapy (CBT) intervention (SPARX: smart, positive, active, realistic, $\mathrm{X}$-factor thoughts) as effective as usual care at reducing depressive symptoms in help-seeking adolescents?

Patients: 187 adolescents aged 12-19 years seeking help for symptoms of mild-to-moderate depression, and deemed in need of treatment by their primary healthcare clinician. Participants were eligible if they had access to a computer, provided written consent and had undertaken a minimum of 1 year of English schooling. Exclusion criteria: severe depression, risk of self-harm, significant morbid or suicidal ideation, intellectual disability or physical limitations, other major mental health disorders, previous (in past 3 months) or current CBT, interpersonal therapy or antidepressants.
\end{abstract}

Setting: Twenty-four primary healthcare sites (general practices, youth clinics and school-based counselling services), seven provincial and urban locations in New Zealand; May 2009 to December 2010.

Intervention: Computerised CBT (SPARX) versus usual care. SPARX is an interactive fantasy game designed to deliver CBT for clinically significant depression, and consisting of seven modules delivered over a 4-7 week period. Usual care consisted of primarily face-to-face counselling delivered by trained counsellors and clinical psychologists.

Outcomes: Primary outcome: change in severity of depressive symptoms (children's depression rating scale-revised, CDRS-R, lower scores indicate less severe symptoms). Non-inferiority was defined as the SPARX group not being having more than a 5.5-point inferior change in the CDRS-R compared to usual care.

Patient follow-up: $91 \%$ at 2 months, $90 \%$ at 5 months; $76 \%$ included in perprotocol analyses (refer notes).
METHODS

Design: Randomised controlled non-inferiority trial.

Allocation: Concealed.

Blinding: Single blinded (outcome assessors blinded).

Follow up period: 5 months (including 2-month treatment period).

\section{MAIN RESULTS}

Perprotocol analysis of the primary outcome showed that SPARX was not inferior to usual care both post-treatment and 3 months later, and this was supported by intention-to-treat analysis. Post-treatment there was no significant difference between SPARX and usual care in change in depressions symptoms, (mean reduction in CDRS-R: 10.32 with SPARX vs 7.59 points with usual care; mean difference: $+2.73 ; 95 \%$ CI -0.31 to $+5.77, p=0.079)$. Intention-to-treat analysis also found no significant difference in change in severity of depression with SPARX group compared to usual care posttreatment (mean reduction in CDRS-R: 9.05 with SPARX vs 7.45 with usual care; mean difference: $+1.60,95 \%$ CI -1.21 to $+4.41, \mathrm{p}=0.264)$. At 3-month post-treatment follow-up, there was still no significant difference between SPARX and usual care for the primary outcome (perprotocol mean difference in CDRS-R change: $-1.28,95 \%$ CI -4.35 to $+1.79, p=0.412$; intention-to-treat mean difference: $-0.75,95 \% \mathrm{CI}-3.62$ to $+2.12, \mathrm{p}=0.609)$.

\section{CONCLUSIONS}

A computerised CBT program (SPARX) for help-seeking adolescents with mild-to-moderate depression is as effective as usual care for reducing symptoms in New Zealand primary care settings.

\section{ABSTRACTED FROM}

Merry SN, Stasiak K, Shepherd M, et al. The effectiveness of SPARX, a computerised self help intervention for adolescents seeking help for depression: randomised controlled non-inferiority trial. BMJ 2012;344:e2598.

Correspondence to: S N Merry, Department of Psychological Medicine and Health Sciences, University of Auckland, Private Bag 92019, Auckland 1142, New Zealand; s.merry@auckland.ac.nz

Sources of funding: The New Zealand Ministry of Health
$M$ erry and colleagues correctly note that although there is clear evidence of the effectiveness of computerised self-help programs for adults with depression, little is known about the effectiveness of such programs for their adolescent counterparts. This is surprising given the high level of depression among young people, their low level of formal help seeking for depression and the high degree of IT literacy and IT uptake in this age group. Accordingly, the authors developed a computerised cognitive behavioral therapy fantasy game, SPARX, designed to be engaging to young people and evaluated its effectiveness in a multicentre non-inferiority randomised-controlled trial, employing a treatment as usual control and 3-month follow-up. The primary, intention-to-treat, finding was that the reduction in depression symptoms, response rate and remission levels associated with SPARX was at least as great as that seen among adolescents who accessed standard primary healthcare. This finding could have significant policy and practice implications for the delivery of mental healthcare to adolescents. It suggests that SPARX may represent a low-cost alternative to standard primary care for many young people. However, a limitation of the study is that there is no way of knowing if the primary healthcare services themselves were effective. Control participants received usual care in primary care settings with most participants receiving 'counselling'. However, there is no description of the nature of this counselling, whether it involved the delivery of evidence-based treatments or the qualifications of those providing it. Apart from some isolated findings, there was little evidence that SPARX was significantly superior to usual care over 3 months. Thus, although it can be concluded that on average participants would not be worse off receiving SPARX, more data are needed to be sure that the intervention works in these settings. That said, the findings are encouraging, the high level of self-reported adherence in a self-guided programme impressive, and the authors have previously reported pilot findings that suggested that SPARX was more effective than a wait-list control for adolescents 'excluded from mainstream education'. We await more evidence of the effectiveness of this promising programme.

\section{Kathleen Margaret Griffiths}

Centre for Mental Health Research, The Australian

National University, Canberra, Australia 


\section{EBMH}

\section{SPARX computerised CBT is as effective as usual care for mild-to-moderate depression in help seeking adolescents}

Evid Based Mental Health 2012 15: 90 originally published online July 7, 2012

doi: 10.1136/ebmental-2012-100822

Updated information and services can be found at:

http://ebmh.bmj.com/content/15/4/90.full.html

These include:

References This article cites 1 articles, 1 of which can be accessed free at: http://ebmh.bmj.com/content/15/4/90.full.html\#ref-list-1

Email alerting Receive free email alerts when new articles cite this article. Sign up in service the box at the top right corner of the online article.

Topic Articles on similar topics can be found in the following collections Collections

Notes

To request permissions go to:

http://group.bmj.com/group/rights-licensing/permissions

To order reprints go to:

http://journals.bmj.com/cgi/reprintform

To subscribe to BMJ go to:

http://group.bmj.com/subscribe/ 